\title{
Interactive comment on "Winter phytoplankton blooms in the offshore south Adriatic waters (1995-2012) regulated by hydroclimatic events: Special emphasis on the exceptional bloom of 1995” by Mirna Batistić et al.
}

\author{
M. Najdek \\ najdek@cim.irb.hr \\ Received and published: 17 August 2017
}

This interesting paper provides an insight into the evolution of winter phytoplankton blooms in the open waters of the southern Adriatic. The authors explained the occurrences recorded in the past and put them in a context coherent with the recent findings of the very complex hydrodynamics of this area and the satellite imagery data. At that time it was very unlikely that such phenomena, based solely on discrete phytoplankton abundances, could be explained. Nowadays, with the further support of satellite data it is much easier to catch and validate such events and determine their eventual 
regularity.

Interactive comment on Biogeosciences Discuss., https://doi.org/10.5194/bg-2017-205, 2017.

Interactive

comment 